\title{
Erratum to: A Review of Undergraduate Evolution Education in U.S. Universities: Building a Unifying Framework
}

\author{
Jenny D. Lloyd-Strovas • Ximena E. Bernal
}

Published online: 20 September 2012

(C) Springer Science+Business Media, LLC 2012

\section{Erratum to: Evo Edu Outreach \\ DOI 10.1007/s12052-012-0435-9}

On the 10th page of this article, second paragraph in the right column should read as follows:

Finally, there is no expert in the field of university-level evolution education. Based on the 15 publications cited, not a single study shared authors (Table 5), suggesting that these studies were probably side projects or graduate student projects. Once a paper was published, the authors did not follow up their study to further examine the complexity of the relationships detected. C Nelson and $B$ Alters have made substantial contributions discussing this field providing a theoretical framework on the challenges of teaching evolution at the undergraduate level (Nelson 2000, Alters \& Alters 2001, Alters \&
Nelson 2002). Their contribution, however, would benefit from integrating such framework with a strong empirical approach (Ingram \& Nelson 2006). Moreover, there is a vast array of departments represented in the publications, ranging from the obvious biology and education departments to the Museum of Paleontology. Even the universities represented in the publications were different. Only a single university was represented more than once among the authors, University of California at Berkley. These studies, however, were published five years apart and the authors were from different departments, suggesting that these projects do not represent a natural continuation of a growing idea. In summation, there is a strong lack of consistency among those researchers who have published on university-level evolution education.

The online version of the original article can be found at http://dx.doi.org/ 10.1007/s12052-012-0435-9.

\footnotetext{
J. D. Lloyd-Strovas $(\bowtie) \cdot$ X. E. Bernal

Biological Sciences, Texas Tech University,

Box\# 43131, Lubbock, TX, USA

e-mail: jenny.strovas@ttu.edu

X. E. Bernal

Smithsonian Tropical Research Institute,

Apartado 0843-03092, Balboa, Ancón,

Panama, Republic of Panama 